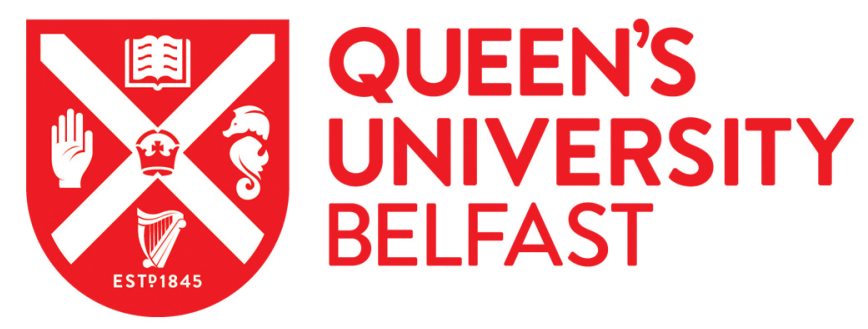

\title{
"There's a Catch-22". The complexities of pain management for people with advanced dementia nearing the end of life: a qualitative exploration of physicians' perspectives
}

De Witt Jansen, B., Brazil, K., Passmore, P., Buchanan, H., Maxwell, D., Mcllfatrick, S. J., Morgan, S. M., Watson, M., \& Parsons, C. (2017). "There's a Catch-22". The complexities of pain management for people with advanced dementia nearing the end of life: a qualitative exploration of physicians' perspectives. Palliative Medicine, 31 (8), 734-742. https://doi.org/10.1177/0269216316673549

Published in:

Palliative Medicine

Document Version:

Peer reviewed version

Queen's University Belfast - Research Portal:

Link to publication record in Queen's University Belfast Research Portal

Publisher rights

Copyright 2016 The Authors.

This work is made available online in accordance with the publisher's policies. Please refer to any applicable terms of use of the publisher.

\section{General rights}

Copyright for the publications made accessible via the Queen's University Belfast Research Portal is retained by the author(s) and / or other copyright owners and it is a condition of accessing these publications that users recognise and abide by the legal requirements associated with these rights.

\section{Take down policy}

The Research Portal is Queen's institutional repository that provides access to Queen's research output. Every effort has been made to ensure that content in the Research Portal does not infringe any person's rights, or applicable UK laws. If you discover content in the

Research Portal that you believe breaches copyright or violates any law, please contact openaccess@qub.ac.uk. 
1 “There's a Catch-22". The complexities of pain management for people with

2 advanced dementia nearing the end of life: a qualitative exploration of physicians'

3 perspectives

4

$5 \quad$ Pain management at end of life in dementia

6 Bannin De Witt Jansen LLB, BSc, MA, PhD. School of Pharmacy, Queen's University

$7 \quad$ Belfast, United Kingdom.

8

9 Kevin Brazil BSc, PhD. School of Nursing and Midwifery, Belfast, United Kingdom.

11 Peter Passmore BSc, MB BCh BAO, MRCP, MD, FRCP (London), FRCP (Glasgow),

12 FRCPI. Centre for Public Health, School of Medicine, Dentistry and Biomedical

13 Sciences, Belfast, United Kingdom.

14

15 Hilary Buchanan MB BCh BAO, DRCOG, MRCGP. Patient and Public Involvement

16 Representative, Carer for a person living with dementia. 
18 Doreen Maxwell MB BCh BAO, DRCOG, MRCGP. Kerrsland Surgery, Belfast, United 19 Kingdom.

20

21 Sonja J. McIlfatrick BSc, MSc, PhD, RGN, RNT. Institute of Nursing and Health 22 Research, Ulster University, United Kingdom. Senior Investigator, All Ireland Institute 23 of Hospice and Palliative Care, Our Lady’s Hospice and Care Services, Dublin. Ireland.

25 Sharon M. Morgan MB BCh BAO, DRCOG, MRCGP. Marie Curie Hospice, Belfast, 26 United Kingdom.

28 Max Watson BD, MB BCh BAO, M Phil, MSc, MRCGP, DRCOG, DCH, DMH.

29 Northern Ireland Hospice, Belfast, United Kingdom.

31 *Carole Parsons PhD, MPharm, MPSNI. School of Pharmacy, 97 Lisburn Road, Belfast,

32 Queen's University Belfast, BT9 7BL, United Kingdom. Email: c.parsons@qub.ac.uk;

33 Telephone: +44 (0) 289097 2304; Fax: +44 (0) 289024 7794. *Corresponding author 
- Pain is prevalent among people with advanced dementia approaching the end of life

37 but is challenging to identify and treat in patients with profound loss of 38 communication who are unable to report the presence, nature and intensity of their 39 pain.

40 - People with advanced dementia are at risk of under-treatment or suboptimal treatment 41 of pain as they approach the end of life.

42 - Untreated pain, or suboptimal treatment of pain, often have deleterious effects on 43 people with advanced dementia including: delirium, sleep disturbance, increased $44 \quad$ confusion and exacerbation of neuropsychiatric symptoms.

\section{$47 \quad$ What this paper adds?}

- This study is the first to explore and describe the complexities and challenges

49 experienced by physicians when prescribing for and managing pain in people with 50 advanced dementia who are approaching the end of life, the impact of these challenges 51 on prescribing and treatment approaches, and the strategies used by physicians to overcome these challenges. 
53 - Physicians' prescribing and treatment decisions were shaped by patients'

54 comorbidities, ageing physiology, existing medication regimens, physical and 55 cognitive impairments and health status.

- Physicians from primary, secondary and hospice care settings made use of knowledge

57 networks across specialties (e.g. palliative care, psychiatry etc.) to inform prescribing 58 and treatment approaches and to overcome the challenges of pain management in this $59 \quad$ vulnerable patient population.

60

61

62

\section{Implications for practice, theory or policy?}

64 - Physicians' goals in end of life care for people with dementia included optimal pain

65 management. However, the complexity of the patient population can make optimal 66 pain management challenging to achieve in practice.

67 - Physicians' narratives revealed an interactive interface across primary, secondary and

68 hospice care settings and across medical specialties through which knowledge and

69 expertise were exchanged to allow palliative and non-palliative doctors to overcome $70 \quad$ the challenges of pain management. 
7

- Promoting cross-specialty knowledge exchange and mentoring can empower nonpalliative care physicians to confidently and effectively manage complex palliative care patients in their respective settings.

\section{Abstract}

Background: Pain management is a cornerstone of palliative care. The clinical issues encountered by physicians when managing pain in patients dying with advanced dementia, and how these may impact on prescribing and treatment, are unknown. Aim: To explore physicians' experiences of pain management for patients nearing the end of life, the impact of these on prescribing and treatment approaches, and the methods employed to overcome these challenges. Design: Qualitative, semi-structured interview study exploring: barriers to and facilitators of pain management, prescribing and treatment decisions, and training needs. Thematic analysis was used to elicit key themes.

84 Settings/Participants: Twenty-three physicians, responsible for treating patients with advanced dementia approaching the end of life, were recruited from primary care $(\mathbf{n}=\mathbf{9})$, psychiatry (n=7) and hospice care (n=7). Results: Six themes emerged: diagnosing pain, complex prescribing and treatment approaches, side-effects and adverse events, route of administration, importance of sharing knowledge and training needs. Knowledge exchange was often practised through liaison with physicians from other specialties. Cross-specialty mentoring, and the creation of knowledge networks were believed to 
91 improve pain management in this patient population. Conclusions: Pain management in 92 end-stage dementia is complex, requiring cross-population of knowledge between 93 palliative care specialists and non-specialists, in addition to collateral information 94 provided by other health professionals and patients' families. Regular, cost- and time95 effective mentoring and ongoing professional development are perceived to be essential 96 in empowering physicians to meet clinical challenges in this area.

98 Keywords: Dementia; Pain; Pain Management; Physicians; Palliative Care; Frail Elderly

\section{Introduction}

101 Dementia is an increasingly challenging global public health concern (1). Worldwide

102 prevalence has reached 46.8 million (2), and projections estimate 74.4 million people 103 living with dementia by 2030 (3). In the United Kingdom (UK), 850,000 people are living 104 with dementia, 19,765 of whom reside in Northern Ireland (NI) (4). The need for 105 appropriate palliative care to manage symptoms, including pain, for people living and 106 dying with dementia is a focus of dementia care strategy in public health policy and is a 107 recognised human right (5-7). 
108 Pain is commonly experienced by people with dementia towards the end of life and is

109 predominantly due to the prevalence of age-associated conditions (e.g. osteo- and

110 rheumatoid arthritis, joint disorders, infection), chronic comorbidities (e.g. heart disease,

111 cancer, diabetes) and distressing symptoms including: nausea, dehydration, dysphagia

112 and dyspnoea (8-12). The deleterious impact of undetected, unresolved or untreated pain

113 in people with moderate and advanced dementia has been reported to result in: delirium,

114 sleep disturbance, increased confusion and exacerbation of neuropsychiatric symptoms

115 (13-20). Previous studies have reported inconsistent approaches to pain management for

116 people with dementia (21-24), primarily due to difficulty assessing and diagnosing pain,

117 and lack of clinical data to guide prescribing for patients approaching the end of life (12,

118 25-27). The under-representation of older adults in clinical trials of analgesics may mean

119 that key outcome measures including toxicity and drug action do not accurately reflect

120 their use in patients with multiple comorbidities and significant physical frailty, and can

121 lead to variability in treatment outcomes (28-33). The inclusion of older, comorbid adults

122 in clinical drug trials is attracting increasing research interest (34-36). Little is known

123 about the challenges encountered by physicians when managing pain in people with

124 advanced dementia nearing the end of life; even less is known about the strategies and

125 resources used to overcome these challenges. This study aimed to elucidate this

126 information as part of a wider programme of research into assessing and managing pain

127 in this complex patient group. 


\section{Aim}

129 To explore physicians' perspectives of the barriers to managing pain in patients nearing

130 the end of life, the impact of these on patient outcomes and the methods employed to

131 overcome these challenges.

132

\section{Methods}

134

135 Setting/Participants

136 Physicians from primary, secondary and hospice care settings were recruited from general

137 practice surgeries ( $n=5)$, hospices $(n=4)$ and hospitals $(n=4)$ across four Health and Social

138 Care (HSC) Trusts in NI. Eligible participants were physicians with responsibility for

139 managing pain in patients with advanced dementia who had died or who were

140 approaching the end of life.

141

142 Sampling and recruitment

143 A pragmatic approach to sampling was taken in light of the number of practising

144 physicians in NI and the range of medical specialities, departments and care settings in 
145 which people with dementia at end of life may be managed, and following a review of 146 sampling frames used in similar studies (37).

147 Seven General Practitioners (GPs) who participated in previous research with members

148 of the research team (Project Management Group [PMG]) were asked to disseminate

149 study information to colleagues in a process of onward referral. In acute care, four 150 consultants (each within a different HSC Trust region) from geriatric medicine ( $\mathrm{n}=2$ ), 151 palliative medicine $(\mathrm{n}=1)$ and psychiatry $(\mathrm{n}=1)$ disseminated study information to eligible 152 hospital physicians within their HSC catchment area. Four Medical Directors (one in each 153 of the participating hospices) circulated study information to hospice physicians. All 154 physicians who contacted the first author regarding participation were recruited to the 155 study. Physicians who assisted with dissemination of study information did not participate 156 in the study.

158 Ethical approval

159 The Office for Research Ethics Committees Northern Ireland (ORECNI) granted ethical 160 approval for the study (14/NI/0013). The study protocol and supporting materials were 161 also approved by hospice ethics committees and HSC Trusts. 
164 Semi-structured, in-person interviews were conducted using an interview guide which

165 allowed flexible exploration of individual experiences within an overarching structure by

166 which commonalities of experience could be identified (38). Interview questions were

167 developed following review of relevant literature and refined in an iterative process of

168 consultation and revision with the PMG which included primary, secondary and hospice

169 care physicians and academics from nursing, palliative care, geriatric medicine and

170 pharmacy. Questions covered: approaches to pain management in people with advanced

171 dementia approaching the end of life, barriers to and facilitators of prescribing for pain

172 and administering analgesics, and training and education needs. The topic guide is

173 presented in Table 1.

174 Physicians were interviewed in their workplace and received Continuing Professional

175 Development (CPD) certificates for participation. Interviews began with a brief

176 exposition of the study aims and objectives, and explanations of ethical approval and the

177 interview process. Each participant provided written, informed consent. Recruitment

178 continued until no further novel data were identified in interviews.

180 Data analysis and validation 
181 Data were collected between June 2014 and September 2015. Interviews were conducted, 182 digitally recorded, transcribed verbatim and analysed by the first author, a researcher with 183 five years' prior training in and experience of designing and conducting qualitative 184 research. Interview duration was on average 18 minutes. Transcripts were checked for 185 accuracy against recordings by KB and HB. Braun and Clarke's paradigm of thematic 186 analysis formed the analytical approach (39). Transcripts were reread several times and

187 line-by-line coding performed to identify recurrent ideas, statements, feelings/sentiments, 188 topics and key words. The first ten scripts were reviewed to ensure that coding uniformly 189 expressed the same ideas, concepts or topics, and a coding frame was developed. Codes 190 from all transcripts were categorised into themes expressing their core concepts. NVivo 19110 (QSR International (UK) Ltd, Cheshire, UK) software was used to facilitate analysis.

192 Data were independently analysed and verified by KB and CP. Final themes and findings 193 were discussed by the PMG.

\section{Results}

196 Twenty-three physicians participated. Physicians’ average age was 42.5 years (range 28

197 to 58 years), and they had an average of 17.5 years' clinical experience (range 5 years to 19831 years). Most were female ( $n=16 ; 69.6 \%)$. Six (26.1\%) had additional postgraduate 199 qualifications. Participant characteristics are presented in Table 2. 
200 Six key themes emerged from the interviews: (1) diagnosing pain, (2) complex 201 prescribing and treatment approaches, (3) side-effects and adverse events, (4) route of 202 administration, (5) sharing knowledge and (6) training needs.

\section{Diagnosing pain}

205 Difficulty diagnosing pain was the most commonly reported barrier to managing pain 206 appropriately in people with advanced dementia approaching the end of life. Loss of the 207 critical patient-physician pain dialogue and the absence of any obvious physical cause of 208 pain (e.g. fracture, wounds) or painful comorbid condition (e.g. cancer) made it difficult 209 to identify and characterise pain.

In a patient with dementia, if you have no history or communication from the patient, it's impossible to get an accurate history to be able to identify the character of pain in the way you would be with a patient who could communicate and had understanding. (PHYS011, GP)

215

216 In the absence of patient report, respondents observed for, and interpreted, behavioural 217 and nonverbal signs. All respondents were acutely aware of the limitations of this 
218 approach, recognising that many of these indicators could also be expressions of fear,

219 anxiety and other non-pain related distress. Most expressed concern regarding potential

220 misinterpretation of these cues and advocated caution in relying on this information.

The signs of pain in this particular patient group could be signs of something else as well, and that's where you have to be very careful to recognise what is their normal behaviour and what has changed or what can we link to pain. (PHYS012,

227 The presence of neuropsychiatric symptoms in these patients further complicated pain diagnosis. Some participants highlighted the potential for misinterpretation of these cues

229 to result in inappropriate treatment, for example, pain relief for emotional distress, whilst

230 others reported uncertainty in decisions to treat the patient for (presumed) pain or for the 231 manifested psychiatric symptoms.

Saw a patient yesterday or two days ago who appeared to be in pain, she had advanced dementia, I felt she was in the last days of her life and she was lying on 
239 The impact of complex comorbidity profiles, neurodegenerative disease, low body mass

240 index and ageing physiology on the pharmacodynamics and pharmacokinetics of many

241 analgesics were key considerations for physicians.

In the very severe stages we get people who can be very, very, physically failed and frail, very low body mass, really no musculature, usually sort of dehydrated, usually with sort of poor cardiac output. Often we're not actually sure how much pain relief is getting in to somebody. Often the difference between what you think the analgesic's going to be and what it actually does to a patient in that kind of stage-the difference is quite substantial. (PHYS03, Consultant Psychiatrist, Secondary Care) 
251 Participants described past experiences in which analgesic effects had been highly 252 unpredictable, resulting in over-treatment for some patients, poor pain control in others 253 and adverse events for a minority.

254

255

256

257

258

259

260

261

262

263

264

265

266

267

268
I've had it where I’ve given one big fellow a very strong painkiller and it floored him; I've seen a wee lady half the size and very frail and actually it wasn't working on her at all. So although I assumed little old ladies need less, it actually went the opposite way. It's really very individual, like with everything, everybody's different (PHYS011, GP).

Most respondents therefore exercised caution in prescribing, particularly when treating new patients, and many followed the principle 'start low and go slow' using paracetamol (acetaminophen) as the preferred first-line treatment, particularly in cases where pain diagnosis was ambiguous.

I would start off with maybe a trial of analgesia but I would start off with the mildest form like paracetamol or something just to see if it made a difference. If they seemed to be responding, I suppose I would use the WHO analgesia ladder and just come up very, very cautiously. (PHYS04, GP) 
270 Pain management was often described as a 'trial and error' process in which pain relief 271 was titrated in response to changes in behaviour, nonverbal cues, vocalisation and levels

272 of consciousness. Psychiatrists and GPs found the World Health Organisation (WHO)

273 Analgesic Ladder (40) helpful in guiding upwards titration; hospice physicians relied on

274 their own previous clinical experience and consultation with colleagues and preferred the 275 national Palliative Adult Network Guidelines (PANG) (41). All physicians regularly 276 prescribed a wide range of analgesics including opioid and compound opioid preparations 277 in a variety of formulations including transdermal patches, intramuscular injections and 278 syringe drivers. GPs and psychiatrists often sought advice or confirmation from 279 specialists such as community hospice, palliative medicine and psychogeriatric 280 practitioners when titrating to higher doses. appreciated. (PHSY014, Psychiatrist, Secondary Care)

If these patients are already on medication for pain it's like where do you go to augment and increase it? So having input from people who are specialists is always

\section{Side-effects and adverse events}


287 Participants described the challenge of prescribing for patients with advanced dementia 288 nearing the end of life as a 'catch-22' situation in which multiple symptom control 289 (including pain), was required, with minimal polypharmacy and avoiding drug 290 interactions and adverse and/or side-effects.

There's a catch twenty-two, there's potential for a lot of interactions with the other medication that they are on, then you face the difficulty with the side effects of medications. So it's really about hitting the balance of making sure that you're doing the patient no harm and treating their pain. It's finding that fine line

Many patients required a greater degree of pain control than could be provided by 299 paracetamol and other simple analgesics, however; codeine and other opioid-based 300 preparations were deemed to carry a high risk of respiratory depression, sedation, constipation and falls, whilst non-steroidal anti-inflammatory drugs (NSAIDs) were associated with risk of gastric bleeding, cardiovascular and stroke events. Side-effects

303 such as constipation (a trigger for onset of acute delirium) and nausea (difficult to detect 304 in the absence of patient self-report), respiratory depression and sedation were considered 305 highly detrimental to patients and contravened participants’ goals of care. 
The likes of the more codeine-based [preparations], it’s the risk of them becoming constipated and making things worse and then I suppose the more heavy morphines and so on, it can just floor them, really wipe them off their feet, more prone to more falls, makes them more drowsy. (PHYS06, Psychiatrist, Secondary Care)

313 Most participants reported that these factors restricted choice of suitable analgesics and

314 often resulted in off-label prescribing. Many GPs and psychiatrists found this challenging

315 due to unfamiliarity with off-label uses for palliative purposes, requiring guidance from 316 palliative care specialists. [Palliative care] has taught me things about using certain agents, midazolam, for example ... something that isn't used widely in my world but it's used widely in [the] palliative world. (PHYS09, Consultant Psychiatrist, Secondary Care) 
323 All participants reported challenges with routes of administration for patients with

324 dementia approaching the end of life. Oral administration was compromised in patients

325 with significant swallowing difficulties, poor gut absorption, nausea and/or vomiting, 326 impaired consciousness (sedation, coma, sleep or drowsiness), or who refused to take 327 medication. ... so perhaps liquids might be refused, tablets may not be taken, they may not be able to take anything orally and they may need medication by a different route. (PHYS015, Consultant in Palliative Care, Hospice)

Many respondents described difficulty encouraging compliance in patients who lacked

334 capacity to engage in discussion regarding the need for symptom control. Syringe drivers, 335 normally considered when oral administration is not viable, presented a number of 336 complications including: forceful removal by agitated patients, lack of available staff experienced in their set-up and use; and in some cases, lack of access to necessary equipment or resources. 
Intravenous [administration] I would have to say we actually rarely use. The problems being that maintaining venous access in somebody who's failing is a problem, it’s often painful and distressing for patient and we open up then risks of infection and so on as well. So we often try and go for, for subcuts if we can, or patches. (PHYS03, Consultant Psychiatrist, Secondary Care)

346 Transdermal patches were a preferred route for overcoming the challenges posed by oral 347 and syringe driver routes. We're maybe more likely to use medications administered by patch through the skin rather than tablets because it's felt to override the challenges of patients being able to take their oral medication reliably. (PHYS017, Consultant in Palliative Care, Hospice)

353

354 Transdermal patches were considered particularly suitable for agitated patients due to their 355 unobtrusive and non-invasive nature and for avoiding difficulties associated with pro-renata (PRN) prescribing in non-verbal patients. 

We would try and use patches sometimes because they're less noticeable to the patient, and if the pain is more stable that can be a way around it. (PHYS015 Consultant in Palliative Care, Hospice)

361

362 Physicians, particularly GPs, highlighted the importance of selecting a route of 363 administration appropriate to a patient's health status and needs, and the need to ensure 364 the availability of healthcare staff appropriately trained to administer and monitor 365 medication via that route. You've an issue with trying to select the type of medication you're going to use and you've an issue then with what way you're going to administer it to them and then who’s going to manage that and monitor it as well. (PHYS022, GP)

370

371 Sharing knowledge

372 All respondents strongly believed that the care of people with dementia approaching the 373 end of life, including pain management, required input from families and healthcare 374 professionals across disciplines. Physicians believed their key responsibility was to 375 provide optimal care for their patients, which included recognising and addressing their 
376 own limitations. Narratives revealed an interactive interface across primary, secondary

377 and hospice care settings and medical specialties through which knowledge and expertise 378 were exchanged.

When it comes to end of life then, we're sharing knowledge, we're the experts in antipsychotic medications and they [palliative medicine physicians] are finding that with people with challenging behaviour, they may need to go that route so we're sharing in terms of cross-populating our knowledge base. (PHYS09, Consultant Psychiatrist, Secondary Care)

386 GPs and psychiatrists sought advice from palliative and hospice care physicians and 387 psychogeriatricians regarding: off-label use of analgesics; titration for patients already 388 receiving pain relief; use of opioid preparations; combining pain-relieving agents; 389 combining analgesics with mild sedation; managing background or breakthrough pain; 390 and routes of administration. Hospice physicians sought guidance for particularly 391 complex patients from neurology, psychogeriatrics, palliative pharmacy and psychiatry.

392 In many cases, participants wanted confirmation of their proposed treatment; receiving 393 support from other specialties and knowing they were 'on the right track' with prescribing 
394 and treatment increased confidence and job satisfaction. Many enjoyed learning from and

395 sharing their expertise with other doctors outside their care setting and medical specialty.

396

397

I would ring, for example, [the hospice] and speak to one of the consultants and I would ask “This is what I'm thinking of doing, do you think this sounds okay?” And then I would get that advice. It just gives me that bit more confidence that the patient's getting maybe the best they could get; because I don't think I'm the best,

401

402 I think I'm a GP and I think a palliative care consultant would be the best. 403

404 Families were perceived to hold key collateral information such as patients' former beliefs 405 about medications, previous pain thresholds, whether they were likely to report pain or 406 'suffer in silence', drug tolerance and allergies, behavioural and nonverbal indicators of 407 pain, and preferred methods of medication delivery.

We very much work with the families because the families usually know this person to the point that they know what they maybe would have wanted or how 
411

412

413

414 Physicians used this knowledge to inform prescribing decisions and to assess treatment 415 response.

416

417

418

419

420

421

422

423

424

425

426

427

428

they are going to respond so we try and get everybody in on the decision-making. (PHYS012, Consultant in Palliative Care, Hospice)

One thing is us giving the families information but the other thing is asking them their perception of whether they perceive that something has helped or not and whether they have noticed any signs of side-effects. They're just better placed—if they're with the person a lot, to identify whether or not the medication has made them confused or that kind of thing. (PHYS017, Consultant in Palliative Care, Hospice)

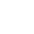

\section{Training needs}

Physicians were dedicated to providing optimal care for patients often within multiple organisational constraints. All respondents believed that the knowledge, skills and expertise required to optimally manage pain in this complex patient population existed within the health professions but were highly dispersed across medical and other 
429 disciplines and care-settings. Physicians considered pharmacology, 430 pharmacotherapeutics, managing pain in patients with challenging behaviours, and 431 distinguishing between pain-related and non-pain related behavioural and psychological 432 symptoms of dementia (BSPD), to be key areas for further training. The majority 433 described physician-to-physician mentoring, in the form of regular meetings of an 434 established network of practitioners from across care settings and disciplines to discuss 435 anonymised real patient cases, as an ideal approach to ongoing professional development. The best would be experiential learning where you can go on a ward round, discuss a case, ask questions, that's the gold standard. (PHYS012, Consultant in Palliative Care, Hospice)

441 Physicians widely believed that this approach would have greater clinical utility and 442 impact than workshops, training days or didactic lectures.

I think that case-based learning is useful because I think it gets people to think about what they do themselves and how they would manage a particular problem. 

the better. (PHYS015, Consultant in Palliative Care, Hospice)

\section{Discussion}

450 To our knowledge this is the first comprehensive exploration of the challenges in pain 451 management for people with advanced dementia approaching the end of life, from 452 physicians' perspectives. People with advanced dementia require the same vigilance in 453 pain management as patients dying with terminal cancer; however, available guidelines 454 offer little advice on how this may be achieved (42-43). Pain control in this patient 455 population can be difficult to achieve and the findings presented here offer greater insight 456 into these challenges from the perspectives of those primarily responsible for this aspect 457 of patient management (44).

458 The gold standard in diagnosing pain is self-report. In advanced dementia, this is rarely 459 available; much of the critical information required to accurately assess, diagnose and 460 target treatment is lost (45). The findings of this study indicate that in the absence of 461 patient report, collateral history from patients' families and other health professionals, 462 along with clinical investigation and interpretation of changes in mood, behaviour, and 463 other nonverbal cues, become important (45-46). However, participants widely 464 acknowledged that many well-recognised behavioural indicators of pain, such as distress, 
465 agitation, wailing, screaming, frowning and apathy, are identical to those expressed 466 through anxiety, boredom, frustration and emotional distress (47). Behavioural 467 interpretation leaves room for misinterpretation and potentially inappropriate treatment 468 (47). Physicians' prescribing decisions were also shaped by patients' comorbidities, 469 ageing physiology, existing medication regimens, physical and cognitive impairments and 470 health status, which were perceived to restrict the range and strengths of analgesics that 471 may be safely tolerated (48). Changes in drug pharmacokinetics and pharmacodynamics, 472 and variation in gut absorption and body fat index may result in over-treatment, delayed 473 effects of pain relief and increased risk of side-effects and adverse events, making 474 management complex and uncertain (48). Most physicians adopted a cautious approach 475 to management. Route of administration was reported as problematic in severely 476 cognitively impaired, dying patients. Loss of swallow, patient refusal and altered 477 consciousness often precluded oral administration, whilst syringe driver use was 478 problematic due to forceful removal by agitated or distressed patients and issues regarding 479 availability of appropriately experienced nursing staff to set up and monitor the 480 equipment. Medication delivery via the transdermal route was considered a better 481 alternative.

482 Physicians across specialties and care settings often sought and shared advice and 483 approaches to pain management. Most respondents strongly believed ongoing CPD via 484 mentoring and knowledge exchange using real-patient cases would empower non- 
palliative specialists to effectively manage patients approaching the end of life. Previous 486 studies have identified a need for further training for healthcare professionals in 487 pharmacology and the use of nonpharmacological treatments, and in discriminating 488 between behavioural and psychological symptoms caused by pain and those which are not 489 pain-related in origin $(44,49)$. The present findings corroborate these suggestions, and 490 provide additional insight into physicians’ training preferences.

491 Sharing knowledge extended beyond health professionals; most participants found 492 collateral history provided by families to be helpful in assessing pain and interpreting 493 nonverbal cues. This echoes other studies which report that good communication, shared 494 knowledge and a mutually respectful relationship between the healthcare team and family 495 carers are critical if treatment is to reflect the interests of the dying patient and achieve 496 clinical goals of care (50-51). Some of the above findings echo those reported in the 497 nursing literature, indicating that medical, nursing and other healthcare staff experience 498 similar challenges in assessment and management of pain for patients with dementia and 499 emphasising the need for effective multidisciplinary working and open communication 500 between healthcare professionals (52-55).

501 There are some limitations with this study. The sampling approach may have resulted in 502 a skewed sample of physicians with an interest in, or past experience of, research 503 participation, who felt comfortable talking about professional challenges. We aimed to 504 recruit physicians across acute specialties; the low participation by physicians outside 
505 psychiatry (possibly due to staffing pressures and workloads) is an acknowledged

506 limitation. Future studies might consider exploring physicians' approaches to pain

507 management for people with advanced dementia with a broader sample of acute

508 physicians. The findings of this study are being used to develop and pilot an intervention

509 aimed at bringing together physicians and other health professionals to engage in

510 interactive real patient case-based learning. It is hoped these findings may encourage

511 further development of strategies to support and empower physicians to provide a gold

512 standard in managing pain for people living and dying with dementia.

\section{Disclosures and Acknowledgements}

515 This research was funded by HSC Research \& Development Division (HSC R\&D),

516 Public Health Agency, Northern Ireland, in association with the Atlantic Philanthropies

517 (Reference: COM/4885/13). The authors would like to thank all research participants,

518 participating hospices and the local collaborators within the HSC Trusts who facilitated

519 and supported this study. Professor Peter Passmore has received funding (educational

520 grants) from Napp, Grünenthal and Pfizer, and has spoken and/or chaired meetings for

521 these companies. Napp, Grünenthal and Pfizer had no role in the development, analysis

522 or reporting of the present study. The other authors have no conflicts of interest to declare.

\section{References}


524 1. World Health Organization and Alzheimer's Disease International. Dementia: a public 525 health priority. 2012. Available from: http://www.who.int/mental_health/publications/ 526 dementia_report_2012/en/. Accessed October 2015.

527 2. Luengo-Fernandez R, Leal J, Gray A. Dementia 2010: the economic burden of 528 dementia and associated research funding in the United Kingdom. 2010. Available 529 from:http://www.alzheimersresearchuk.org/wp-

530 content/uploads/2015/01/Dementia2010Full.pdf Accessed October 2015.

531 3. Prince M, Wimo A, Guerchet M, Ali G, Wu Y, Prina M. World Alzheimer Report 532 2015: The Global Impact of Dementia An analysis of prevalence, incidence, cost and 533 trends. 2015. Available from: http://www.alz.co.uk/research/world-report-2015. 534 Accessed October 2015.

535 4. Prince M, Knapp M, Guerchet M, et al. Dementia UK: Update. 2014. Available from: 536 https://www.alzheimers.org.uk/site/scripts/documents_info.php?documentID=2759.

537 Accessed October 2015.

538 5. Department of Health. Living well with dementia: a National Dementia Strategy. 2009.

539 Available from:

540 https://www.gov.uk/government/uploads/system/uploads/attachment_data/file/168220/d

541 h_094051.pdf. Accessed October 2015. 
542 6. Department of Health, Social Services and Public Safety. Improving dementia services

543 in Northern Ireland: a regional strategy. 2011. Available from:

544 https://www.dhsspsni.gov.uk/publications/improving-dementia-services-northern-

545 ireland-regional-strategy. Accessed October 2015.

546 7. van der Steen JT, Radbruch L, Hertogh CM et al. White paper defining optimal

547 palliative care in older people with dementia: A Delphi study and recommendations from

548 the European Association for Palliative Care. Palliat Med 2014; 28: 197-209.

549 8. Husebo BS, Strand LI, Moe-Nilssen R et al. Who Suffers Most? Dementia and Pain in

550 Nursing Home Patients: A Cross-sectional Study. J Am Med Dir Assoc 2008; 9: 427-433.

551 doi:http://dx.doi.org/10.1016/j.jamda.2008.03.001.

552 9. Bunn F, Burn A-M, Goodman C et al. Comorbidity and dementia: A scoping review

553 of the literature. BMC Med 2014; 192. doi:10.1186/s12916-014-0192-4.

554 10. Klapwijk MS, Caljouw MAA, Van Soest-Poortvliet MC, Van Der Steen JT, 555 Achterberg WP. Symptoms and treatment when death is expected in dementia patients in 556 long-term care facilities. BMC Geriatr 2014; 14:99. doi:10.1186/1471-2318-14-99.

557 11. Mitchell SL, Teno JM, Kiely DK, Shaffer ML, Jones RN et al. The clinical course of 558 advanced dementia. N Engl J Med 2009; 361: 1529-1538. 
559 12. Hendriks SA, Smalbrugge M, Galindo-Garre F, Hertogh CMPM, van der Steen JT.

560 From Admission to Death: prevalence and course of pain, agitation, and shortness of

561 breath, and treatment of these symptoms in nursing home residents with dementia. J Am

562 Med Dir Assoc 2015; 16: 475-481. doi:10.1016/j.jamda.2014.12.016.

563 13. Pieper MJC, van Dalen-Kok AH, Francke AL et al. Interventions targeting pain or

564 behavior in dementia: A systematic review. Ageing Res Rev 2013; 12: 1042-1055.

565 doi:10.1016/j.arr.2013.05.002.

566 14. Ahn H, Garvan C, Lyon D. Pain and aggression in nursing home residents with

567 dementia: Minimum data set 3.0 analysis. Nurs Res 2015; 64: 256-263.

568 15. Cipher DJ, Clifford PA. Dementia, pain, depression, behavioral disturbances, and

569 ADLs: Toward a comprehensive conceptualization of quality of life in long-term care. Int

$570 \quad$ J Geriatr Psychiatry 2004; 19: 741-748.

571 16. Hadjistavropoulos T, Voyer P, Sharpe D, Verreault R, Aubin M. Assessing Pain in

572 Dementia Patients with Comorbid Delirium and/or Depression. Pain Manage Nurs 2008;

573 9: 48-54. doi:10.1016/j.pmn.2007.12.004.

574 17. Deschenes CL, McCurry SM. Current treatments for sleep disturbances in individuals

575 with dementia. Curr Psychiatry Rep 2009; 11: 20-26. 
576 18. Passmore $\mathrm{P}$, Cunningham E. Pain assessment in cognitive impairment. J Pain 577 Palliative Care Pharmacother 2014; 28: 305-307. doi:10.3109/15360288.2014.941136.

578 19. Khachiyants N, Trinkle D, Son SJ, Kim KY. Sundown syndrome in persons with 579 dementia: An update. Psychiatry Investig 2011; 8: 275-287. doi:10.4306/pi.2011.8.4.275.

580 20. Lin P-C, Lin L-C, Shyu Y-L, Hua M-S. Predictors of pain in nursing home residents 581 with dementia: A cross-sectional study. J Clin Nurs 2011; 20: 1849-1857. 582 doi:10.1111/j.1365-2702.2010.03695.

583 21. De Souto Barreto P, Lapeyre-Mestre M, Vellas B, Rolland Y. Potential underuse of 584 analgesics for recognized pain in nursing home residents with dementia: A cross-sectional 585 study. Pain 2013; 154: 2427-2431. doi:10.1016/j.pain.2013.07.017.

586 22. Tan EC, Jokanovic N, Koponen MP et al. Prevalence of analgesic use and pain in 587 people with and without dementia or cognitive impairment in aged care facilities: A 588 systematic review and meta-analysis. Curr Clin Pharmacol 2015; 10: 194-203.

589 23. Bell ML. Postoperative pain management for the cognitively impaired older adult. 590 Semin Perioper Nurs 1997; 6: 37-41. 
591 24. Morrison RS, Siu AL. A comparison of pain and its treatment in advanced dementia 592 and cognitively intact patients with hip fracture. J Pain Symptom Manage 2000; 19: 240593248.

594 25. Bruneau B. Barriers to the management of pain in dementia care. Nurs Times 2014; 595 110: 12-15.

596 26. Krumm N, Larkin P, Connolly M, Rode P, Elsner F. Improving dementia care in 597 nursing homes: Experiences with a palliative care symptom-assessment tool (MIDOS). 598 Int J Palliative Nurs 2014; 20: 187-192.

599 27. Borgsteede SD, Deliens L, Zuurmond WWA et al. Prescribing of pain medication in 600 palliative care. A survey in general practice. Pharmacoepidemiol Drug Saf 2009; 18: 16601 23. doi:10.1002/pds.1678.

602 28. Lövheim H, Karlsson S, Gustafson Y. The use of central nervous system drugs and 603 analgesics among very old people with and without dementia. Pharmacoepidemiol Drug 604 Saf 2008; 17: 912-918. doi:10.1002/pds.1600.

605 29. Husebo BS, Ballard C, Sandvik R, Nilsen OB, Aarsland D. Efficacy of treating pain 606 to reduce behavioral disturbances in residents of nursing homes with dementia: Cluster 607 randomised clinical trial. BMJ 2011; 343: d4065. 
608 30. McLachlan AJ, Bath S, Naganathan V et al. Clinical pharmacology of analgesic

609 medicines in older people: Impact of frailty and cognitive impairment. $\mathrm{Br} \mathrm{J}$ Clin

610 Pharmacol 2011; 71: 351-364. doi:10.1111/j.1365-2125.2010.03847.

611 31. Mallet L, Spinewine A, Huang A. The challenge of managing drug interactions in 612 elderly people. Lancet 2007; 370: 185-191.

613 32. McLachlan AJ, Hilmer SN, Le Couteur DG. Variability in response to medicines in 614 older people: Phenotypic and genotypic factors. Clin Pharmacol Ther 2009; 85(4): 431615 433. doi: 10.1038/clpt.2009.

616 33. Brenes-Salazar JA, Alshawabkeh L, Schmader KE, Hanlon JT, Forman DE. Clinical 617 pharmacology relevant to older adults with cardiovascular disease. J Geriatr Cardiol 618 2015; 12(3): 192-195. doi:10.11909/j.issn.1671-5411.2015.03.018.

619 34. Crome P, Lally F, Cherubini A. et al. Exclusion of older people from clinical trials: 620 professional views from nine European countries participating in the PREDICT study.

621 Drugs Aging 2011; 28: 667-77. doi:10.2165/11591990-000000000-00000.

622 35. Crome P, Cherubini A, Oristrell J. The PREDICT (increasing the participation of the 623 elderly in clinical trials) study: the charter and beyond. Expert Rev Clin Pharmacol 2014; 624 7: 457-468. doi:10.1586/17512433.2014.922864. 
625 36. Watts G. Why the exclusion of older people from clinical research must stop. 626 BMJ 2012; 344: e3445. doi:http://dx.doi.org/10.1136/bmj.e3445.

627 37. Johnston S, Liddy C, Hogg $\mathrm{W}$ et al. Barriers and facilitators to recruitment of 628 physicians and practices for primary care health services research at one centre. BMC 629 Med Res Methodol 2010; 10: 109. doi:10.1186/1471-2288-10-109.

630 38. Britten N. Qualitative interviews in healthcare. In: Pope C, Mays N, eds. Qualitative 631 research in health care. London: BMJ Books, 1999: 11-19.

632 39. Braun V, Clarke V. Using thematic analysis in psychology. Qual Res Psychol 2006; 633 3: 77-101. doi:10.1191/1478088706qp063oa.

634 40. World Health Organisation. WHO's Pain Relief Ladder. Available at: 635 http://www.who.int/cancer/palliative/painladder/en/. Accessed December 2015.

636 41. Watson M, Lucas C, Hoy A, Back I, Armstrong P. Palliative Adult Network 637 Guidelines. Available at: http://book.pallcare.info/. Accessed October 2015.

638 42. Scott S, Sampson EL, Jones L. The Compassion programme: Looking at improving 639 end-of-life care for people with advanced dementia. Int J Palliative Nurs 2012; 18: $212-$ 640216. 
641 43. National Institute for Health and Care Excellence. Dementia: supporting people with 642 dementia and their carers in health and social care. 2006. Available from: 643 https://www.nice.org.uk/guidance/cg42. Accessed October 2015.

644 44. Achterberg WP, Pieper MJC, van Dalen-Kok AH et al. Pain management in patients 645 with dementia. Clin Interv Aging 2013; 8: 1471-1482. doi:10.2147/CIA.S36739.

646 45. McAuliffe L, Brown D, Fetherstonhaugh D. Pain and dementia: an overview of the 647 literature. Int J Older People Nurs 2012; 7: 219-226. doi:10.1111/j.1748$648 \quad 3743.2012 .00331$.

649 46. American Geriatrics Society. Panel on persistent pain in older persons: The 650 management of persistent pain in older persons. J Am Geriatr Soc 2002; 50: S205-S224.

651 47. Ballard C, Creese B, Corbett A, Aarsland D. Atypical antipsychotics for the treatment 652 of behavioral and psychological symptoms in dementia, with a particular focus on longer 653 term outcomes and mortality. Expert Opin Drug Saf 2011; 10: 35-43.

654 48. McLachlan AJ, Bath S, Naganathan V et al. Clinical pharmacology of analgesic 655 medicines in older people: impact of frailty and cognitive impairment. $\mathrm{Br} \mathrm{J}$ Clin 656 Pharmacol 2011; 71: 351-64. 
658 care providers working in long-term care facilities with regard to pain management. Pain 659 Res Manage 2012; 17: 341-346.

660 50. Dening KH, Jones L, Sampson EL. Preferences for end-of-life care: A nominal group 661 study of people with dementia and their family carers. Palliat Med 2013; 27: 409-417.

662 51. Lopez RP, Mazor KM, Mitchell SL, Givens JL. What is family-centered care for 663 nursing home residents with advanced dementia? Am J Alzheimers Dis Other Demen 664 2013; 28: 763-768. doi:10.1177/1533317513504613.

665 52. Burns M, McIlfatrick S. Nurses' knowledge and attitudes towards pain assessment for 666 people with dementia in a nursing home setting. Int J Palliat Nurs 2015; 21: 479-487

667 53. Burns M, Mcllfatrick S. Palliative care in dementia: literature review of nurses' 668 knowledge and attitudes towards pain assessment. Int J Palliat Nurs 2015; 21: 400-407

669 54. Fry M, Chenoweth L, Arendts G. Assessment and management of acute pain in the 670 older person with cognitive impairment: a qualitative study. Int Emerg Nurs 2016; 24: $671 \quad 54-60$

67255. Birch D, Draper J. A critical literature review exploring the challenges of delivering 673 effective palliative care to older people with dementia. J Clin Nurs 2008; 9: 1144-1163

674 